\title{
2. IDEC: The 2007 General Election through a Whole-of-Government Approach
}

\author{
Paul B.B. Bengo
}

\section{The concept}

The staging and the conduct of the 2007 general election in Papua New Guinea was a success story as a result of effective cooperation and coordination among the relevant state organizations at national and provincial levels.

This effective cooperation and coordination was forged and fostered by the electoral commissioner, who insisted on the need for a whole-of-government approach in the planning, staging, and conduct of the general election.

\section{Implementation and achievements}

In the implementation of this initiative an Inter-departmental Electoral Committee (IDEC) was established at the national level while provincial election steering committees were established in the provinces, chaired by provincial administrators.

Through the operation of IDEC and provincial election steering committees it was possible to achieve a number of significant administrative and management outcomes. Among these five stand out.

- In the staging and conduct of the election, there was compliance with nearly all constitutional and legal requirements, such as the general provisions of the Constitution, the Organic Law on National and Local-level Government Elections, the Organic Law on the Integrity of Political Parties and Candidates, and the Criminal Code.

- An extensive and effective public awareness was conducted covering voter enrolment and registration, the limited preferential voting system, voter turnout at polling venues, the need for respect and orderliness in the electoral process, etc. 
- An effectively coordinated security plan was drawn up among the disciplined forces for a free and fair election.

- There was a well-coordinated government effort with support from international governments and donor agencies.

- Superb teamwork mounted at the national level and supported by disciplined and dedicated members of staff from the provincial governments and their respective administrations succeeded in mobilizing and coordinating the resources at the disposal of governments.

Through these administrative and management strategies we were able to bring greater integrity and transparency to the entire electoral process. A number of Papua New Guinean authors will address some of these issues.

Let me deal specifically with the provisions of the Organic Law on the Integrity of Political Parties and Candidates relating to the election.

Section 27 of the organic law allows only registered political parties to endorse or nominate and participate in elections. As required by Section 40, the registrar published in the National Gazette (3 May 2007) the necessary details of registered political parties.

Section 63 of the organic law obliges the electoral commissioner, upon the return of writs for the general election, to officially advise the head of state on important matters relating to the staging and conduct of the election (National Gazette 3 May 2007).

The advice indicated to the head of state which registered political party had the greatest number of candidates declared elected. Based on this advice the head of state issued an invitation to the National Alliance to form government (National Gazette 10 August 2007).

With regard to the whole-of-government approach, the government of Papua New Guinea has recognized the initiative of the electoral commissioner and has now funded IDEC and the provincial steering committees to continue on a permanent basis. (IDEC was convened later in 2007 to coordinate arrangements for local-level government elections.)

It is the intention of the Papua New Guinea Electoral Commission and myself to institutionalize the IDEC initiative so that it can be an effective administrative mechanism to assist the commission to plan, stage and conduct elections in Papua New Guinea at both national and provincial levels. 